\title{
Axillary arch muscle
}

\section{Sharma $\mathbf{T}^{1}$, Singla RK ${ }^{2}$, Agnihotri $\mathbf{G}^{3}$, Gupta $\mathrm{R}^{4}$}

${ }^{1}$ Professor \& Head, ${ }^{2}$ Associate Professor, ${ }^{3}$ Lecturer, ${ }^{4}$ Junior Resident, Department of Anatomy, Government Medical College, Amritsar, India

\begin{abstract}
Langer'arch is one of the rare muscular variation in the axillary region. In the present article, a case of 50 year old male cadaver with axillary arch in the right axillary region is being reported. It originated from anterior border of latissimus dorsi and merged with short head of biceps brachii. The embryological derivation, genetic basis and clinical implication of this muscular variant are also discussed.
\end{abstract}

Key words: Axillary arch muscle, langer's arch, Panniculus carnosus

$\mathrm{D}$ uring the past two centuries, the anatomical variations of the axilla have been described in both text books of human anatomy and operative surgery. Interest has been further stimulated by increasing surgical importance of this region during axillary surgery for breast cancer, reconstruction techniques and axillary bypass operations ${ }^{1}$.

One of the rare anatomic variations within the axilla is a muscular band extending from the latissimus dorsi muscle to pectoralis major muscle, called variously as Langer's axillary arch, aschelsbogen, axillopectoral muscle, pectodorsal muscle or arcus axillaris. Many variants of this muscular anomaly have been observed like the muscle adhering to the coracoid process of scapula, medial epicondyle of humerus, teres major, long head of triceps brachii, caracobrachialis, biceps brachii and pectoralis minor. The most commonly described form of this muscle extends from latissimus dorsi to pectoralis major, the short head of biceps brachii, or to coracoid process. This variation occurs in about $7 \%$ of the population, more common among Chinese than in Caucasians and more common in females than in males ${ }^{2}$. It is usually bilateral but can occur unilaterally ${ }^{3}$.

\section{Case report}

During the routine undergraduate dissection of the right axillary region of a 50 year old male cadaver, a muscular slip was encountered which originated from the anterior border of the latissimus dorsi and crossed the axillary vessels and cords and branches of brachial plexus. It then merged with the short head of biceps brachii (Fig 1). It was $10 \mathrm{~cm}$ in length and $1.5 \mathrm{~cm}$ in width at its broadest point. It was identified as axillary arch muscle. An attempt was made to find similar muscle on the contralateral limb but no such muscle could be seen there.

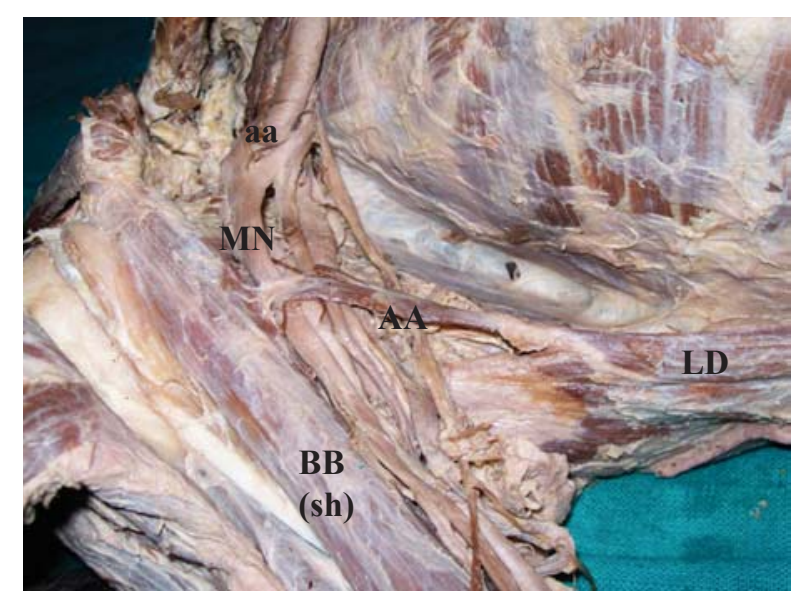

Fig 1: right axillary arch muscle

(aa) - Axillary Artery,

$(\mathrm{MN})$ - Median Nerve,

(AA) - Axillary Arch,

(LD) - Latissimus Dorsi,

BB (sh) - Short head of biceps brachii.

Correspondence

Dr. Rimpi Gupta

Department of Anatomy

Government Medical College

Amritsar-143001, Punjab, INDIA

E-mail: dr.rimpigupta15@gmail.com 
Table 1: The incidence of the axillary arch muscle reported in the literate

\begin{tabular}{|c|c|c|c|c|}
\hline Author (year) & No. of arches & No. of subjects & Percentage & Population \\
\hline Serpell and Baum ${ }^{6}(1991)$ & 4 & 2000 & 0.2 & Caucasian \\
\hline Clarys et al ${ }^{7}(1996)$ & 16 & 183 & 8.7 & Caucasian \\
\hline Turgut et al ${ }^{5}(2005)$ & 1 & 26 & 3.8 & Caucasian \\
\hline
\end{tabular}

\section{Discussion}

The axillary arch was first identified by Alexander Ramsay in 1795, though reported in 1812. However it was Langer $(1846)^{4}$ who described the muscle more accurately such that thereafter it became known as Langer's arch.

Langer's arch usually is seen as a single band, but it can divide into double or, rarely, multiple structures which extend across the axilla. In its complete and common form, it arises from latissimus dorsi and inserts into the trilaminar tendon of pectoralis major on the humerus, while in its incomplete form it presents with varying insertions into pectoralis minor, coracobrachialis, long or short heads of biceps, teres major, coracoid process, first rib, axillary fascia or coracobrachialis fascia ${ }^{2}$. The nerve supply to this variant muscle is most commonly from medial pectoral nerve or thoracodorsal nerve ${ }^{5}$.

Different studies have shown its frequency varying from $0.25 \%$ to $43.8 \%$ depending on the population studied (Table 1).

\section{Ontogeny}

The embryological derivation of Langer's arch remains unknown, but the most reliable theory supports its origin from the panniculus carnosus, which is an embryological remnant of a more extensive sheet of skin associated musculature, lying at the junction between the superficial fascia and subcutaneous fat. This structure is well developed in lower mammals, particularly rodents, while in higher primates and humans it is evident only as muscle such as platysma and dartos; in the remainder of body it becomes vestigial ${ }^{8}$. In lower mammals, the panniculus carnosus is highly developed to form the pectoral group of muscles. However, in man, it has regressed because its functional importance decreased during evolution in favour of wider upper limb mobility ${ }^{9}$. In humans, Langer's arch is therefore the most common embryologic remnant of the panniculus carnosus in the pectoralis group of muscles ${ }^{2}$.

\section{Genetic basis}

A possible genetic basis has been pointed out by Aziz $(1980)^{10}$ who found it bilaterally in a patient of trisomy 13 .

\section{Clinical implications}

Langer's arch can occasionally be palpable during routine clinical examinations when, presenting as an axillary mass, it can be confused with enlarged lymph nodes or soft tissues tumours. Clinical features such as intermittent axillary vein obstruction or a finding of fullness within the axilla itself can be clinically useful but MRI scan may be required to confirm the diagnosis ${ }^{11}$. Clinically it has been implicated in costoclavicular compression syndrome, axillary vein entrapment, median nerve entrapment, hyperabduction syndrome, thoracic outlet syndrome and shoulder instability syndrome ${ }^{3,7}$. Langer's arch is usually asymptomatic and its main importance is the confusion it can cause during routine axillary surgery for breast cancer. The presence of muscular or tendinous fibres of the arch can impede adequate exposure of the true axillary fat and in particular may limit the access to the lower lateral group of lymph nodes, thus resulting in an incomplete clearance of the axilla. Furthermore, the identification of langer's arch or its remnant may be of particular importance when performing sentinel node biopsy, because for the need of adequate exposure and good haemostasis during this procedure.

Although lymph node dissection for breast cancer is the most common type of surgery performed in axilla, there are surgical procedures in this area, which may be effected if Langer's arch is encountered. Access for bypass surgery using the axillary vessels may be compromised if there is failure to identify Langer's $\operatorname{arch}^{6}$. Ischaemic necrosis has complicated latissimus dorsi breast reconstruction if the thoracodorsal pedicle is stretched or compressed by an unsuspected axillary $\operatorname{arch}^{12}$.

\section{Conclusion}

It is important that surgeons operating in the axilla be aware of this not uncommon anatomic variant. When present, Langer's arch should always be accurately identified and formally divided to allow adequate exposure of axillary contents to achieve a complete lymphatic dissection and preserve vascular, lymphatic and nervous structures. 


\section{References}

1. Besana-Ciani I, Grenall MJ. Langer's axillary arch: Anatomy, embryological features and surgical implications. Surgeon. 2005; 3(5): 3257.

2. Bonastre V, Rodriguez-Niedenfuhr M, Choi D, Sanudo JR. Coexistence of a pectoralis quartus muscle and an unusual axillary arch: case report and review. Clin Anat. 2002;15:366-70.

3. Merida-Velasco JR, Rodriguez Vasquez JF, Merida-Velasco JA, Sobrado Perez J, Collado JJ. Axillary arch: potential cause of neurovascolar compression syndrome. Clin Anat. 2003;16: 514-9.

4. Langer C. Zur Anatomie Des Musculus Latissimus Dorsi. Oesterreichische Med Wochenschrift. 1846; 15:454-8.

5. Turgut HB, Peker T, Gulekon N, Anil A, Karakose M. Axillopectoral muscle (Langer's muscle). Clin Anat. 2005; 18: 220-3.

6. Serpell JW, Baum M. Significance of Langer's axillary arch in axillary dissection. Aust N Z J Surg. 1991;61(4):310-2.

7. Clarys JP, Barbaix E, Van Rompaey H, Caboor D. The muscular arch of the axilla revisited: its possible role in the thoracic outlet and shoulder instability syndromes. Man Ther. 1996; 1(3): 133-9.
8. Salmons S. Muscle. In: Gray's Anatomy; The Anatomical Basis of Medicine and Surgery. Williams PL, Bannister LH, Berry MM, Collins P, Dyson M, Dussek JE et al (editors). 38th edition. New York and London: Churchill Livingstone, 1995.p. 782-3.

9. Bergman RA, Afifi AK, Ryosuke M. Panniculus Carnosus. Opus IÂ: Muscolar System. In: Illustrated Encyclopedia of Human Anatomic Variation [book on the internet]. US: University of Iowa [cited 2009may]. Available form: http:// www.janela1.com/vh/docs/v0000978.htm

10. Aziz MA. Anatomical defects in a case of trisomy 13 with a $\mathrm{D} / \mathrm{D}$ translocation. Teratology. 1980; 22: 217-27.

11. Suzuma T, Sakurai T, Yoshimura G, Umemura T, Shimizu Y, Yang QF et al. Magnetic resonance axillography for preoperative diagnosis of the axillopectoral muscle (Langer'axillary arch): a case report. Breast Cancer. 2003;10(3):281-3.

12. Miguel M, Llusa M, Ortiz JC, Porta N, Lorente M. The axillopectoral muscle (of Langer): report of three cases. Surg Radiol Anat. 2001;23(5):341-3. 